\title{
Guest Editorial Science, Spirit, and the Soul
}

\author{
Arthur M. Young, D.Sc.(Hon.), Ph.D.(Hon.) \\ Institute for the Study of Consciousness
}

\section{Intention}

Current science is extremely bold when it comes to saying what happened nanoseconds after the Big Bang. It has invented some one hundred particles that haven't been observed to explain some 32 that have been observed, most for a brief lifetime of less than a billionth of a second. But science doesn't explain consciousness. It doesn't explain extrasensory perception. It doesn't explain life; and its explanation of evolution is far from satisfactory.

And if it be excused from these difficult questions on the grounds that they are not the business of science, it still can be charged not only with neglecting an important subject, but with intimidating witnesses who would like to testify.

We cannot, in this day and age, get along without science. That is because science, which started humbly to deal with aspects of nature that could be measured objectively, has contributed enormously to the understanding of the subjects it has been instrumental in developing: physics, chemistry, biology, mathematics, astronomy. In fact, it has gained a momentum, a reputation, that leads the public to expect it to do what was not in its original purview. Even scientists themselves have become so enamored of the techniques and formulations successful with inert bodies that they do not hesitate to apply those techniques to areas where they are not appropriate.

Arthur Young is the founder of the Institute for the Study of Consciousness in Berkeley, CA. Requests for reprints should be sent to Dr. Young at Robert Briggs Associates, Box 9, Mill Valley, CA 94942. 
Those who wish to explore the new land-consciousness, life, etc.may conclude that science has no place in such a quest, which would involve what Francis Bacon called primary causes. But that answer would be too simple. Currently there are difficulties at the frontier of physics that indicate that all is not well at the foundations of science itself. Problems such as the effect of the observer on what is observed, the breakdown of the principle of locality in the Einstein-PodolskyRosen experiment, and the virtual (unobservable) nature of the photon, all call for a better understanding of basic assumptions that might involve consciousness. Science has inadvertently stumbled into the terra incognita of primary causes.

These in-house problems, which threaten the rationality of science, make most scientists even more touchy and defensive when it comes to giving credence to what is regarded as witchcraft and superstition. Findings there are aplenty: extrasensory perception, distant viewing, near-death experiences, precognitive dreams, metal bending, etc. But these are cold winds to science, which responds by buttoning up its coat and refusing to stick its neck out.

Clearly, the purpose of science and of consciousness research and exploration should be one and the same, and the difficulties that they share could lead to a constructive partnership. But at this writing, there is no platform for a common debate, much less agreement as to how to carry out such a program. Any synthesis of science and consciousness research that has occurred has been done by individuals, each after their own fashion and in their own subjective terms. Such individual solutions do not furnish a language for communication or a formalism on which to build.

In the absence of such a formalism, even if we were able to reach an agreement that the many different world views that exist or have existed-polytheism, monotheism, science, witchcraft, astrology, and so on-were each valid in their own way, we would still be unable to join forces in the quest for answers to the great problem: "Why are we here and what is man?"

The momentum of the scientific endeavor leads most scientists to dismiss these as improper questions. Other scientists might answer by expression of their religious views, in which case I would have to be content. But how can they be content, since they are serving two masters? That is the dilemma of the scientist, and it is shared by most of us. We have come to rest our faith on science, and on these questions science has no answers. That, I think, is the neurosis of the West and of the modern world.

Not to press this as an accusation, but to use it as a clue, let me go a 
step further, to point out that evidence for that faith in science comes just as much from the nonscientist camp. Those interested in consciousness talk about psychic "energy," "vibrations," and even consciousness or instinct as a "field." Not only is this borrowing scientific terminology for improper usage, and hence not helpful for enlisting the interest of science, but it is also misleading to nonscientists.

I have always had great respect for the precise language of science, but I do not feel science as it is generally understood is appropriate as a basis for an intelligent approach to problems such as the nature of extrasensory perception and life after death. When I first began to investigate those questions in the late 1940s, I thought that perhaps we should start all over, begin with a clean slate and reconstruct our picture of the world. It did not then occur to me that the doctrine of an exclusively objective universe was not only mistaken, but was a wrong interpretation by science of its own findings.

My first approach was to seek some unrecognized energy to explain extrasensory perception, and I attended to what theories there were in the field. Wilhelm Reich had his orgone energy; Oscar Brunler had his bioelectric field; Karl von Reichenbach his odic force. There were quite a variety of types of energy that under scrutiny were defined differently and could not be confirmed.

Then I realized that in most cases where psychic "powers" were utilized-healing, influencing plant growth, dowsing, etc.-regardless of the energy involved, the intention of the operator was a critical factor. For instance, in radionics, a system of "psychic therapy" involving instruments and dials, I found it didn't matter whether the machine was plugged in, as long as the operator thought it was. So I called this the operator factor. On the supposition that there must be something in science that anticipated this discovery, I began to look for a correlate to this "intention," this purpose.

The basic vocabulary of science is the measure formulas of physics, which reduce everything to mass, length, and time. Clearly, it would be too simple to identify intention with any of those three parameters alone. Of the six measure formulas containing all three, however, one was promising, and that was the formula for action, $\mathrm{ML}^{2} / \mathrm{T}$. Other formulas, such as those for energy and force, are well recognized in science, but action, particularly action at a distance, while recognized, has always been one of its greatest enigmas. We can understand or at least accept as plausible the fact that when a moving body collides with a body at rest, the motion of the first is transferred to the second; in that case there is the mass to carry the energy. But light, the carrier of action, has no rest mass; it conveys energy and leaves no residue. 
Like the arrow in the symbolism of the archer, it acts to reach a distant goal.

The importance of action emerged when Max Planck discovered that action comes in wholes. That was the discovery that led to quantum theory, a major revolution in physics. These wholes are photons (light), or quanta of action. The unit of action, the product of energy times time, is always the same. The energy may be very small, or it might be very large, but the associated time, which for the photon is its period, is inversely proportional to the energy. It is very short for a photon of high energy, roughly $10^{-22}$ seconds for a photon with enough energy to create a proton, and proportionally long for a very low-energy photon, roughly $1 / 10$ second for a wavelength close to the circumference of the earth.

Why should light come in wholes? The atomic theory, first enunciated by Democritus, stated that matter comes in wholes, which he called atoms, meaning indivisible units. But it turned out that what he called atoms could be divided or reduced to protons and electrons. These, the only permanent material particles, are in one respect more deserving of the name atoms because they are more fundamental than what we call atoms (hydrogen, oxygen, carbon, etc.). Atoms are the smallest units into which matter can be divided and still keep its identity. Protons and electrons have no identity, and are not truly separate; they are linked by an enormous force, $10^{39}$ times gravity.

However, having come this far, we could ask: What is most fundamental? While proton and electron are more fundamental than atoms, they are still a duality, or more correctly a quadruplicity, because their creation involves antiparticles, antiproton and positron, in which the charges are reversed.

What's that again? Their creation? Yes, and the fact that they are created implies what is yet more fundamental: that which creates them. And that, it turns out, is the photon or quantum of action. Material particles created from action, from pure action! Incredible, yet there it is, a finding from material science. If that isn't a surprise ending to the "whodunit" of science, I don't know what is.

Let's put this together. Of all the things that science deals with, things that can be cut up in pieces, measured, weighed, located, there is one "no thing" that cannot be located, measured, weighed, cannot even be seen without being annihilated, a no thing that is not in space or time. That is action. It comes only in wholes. What does that mean? It means the same as with a human action or decision; you cannot jump out of bed 1.4142 times or decide to get married 3.9 times.

This is an unexpected confirmation that we are on the right track. In 
looking for the scientific equivalent to purpose, we find that action, which comes in wholes, is the one thing that cannot be divided or measured. That is ontologically satisfactory, because it is only from such a whole that things can begin.

But there is another aspect of the quantum of action that confirms its correlation to purpose or intention. That is uncertainty, and it is difficult to conceptualize. It was Werner Heisenberg who, in 1925, 25 years after the quantum of action was discovered, realized that when we try to locate an electron we must throw light on it, and that disturbs either its position or its momentum. If we use short-wave light to get the position accurately, the large energy of the light disturbs the velocity; if we use long-wave light of low energy we get a less accurate estimate of position. The product of these two inaccuracies or errors is a unit of uncertainty, and this unit has the same formulation, MV times L, as Planck's quantum of action.

Take your time to consider this enigma; it took science quite a while to get used to it. But save some time for going the next step: to realize that this uncertainty, which is the inability of the observer to predict what is going to happen, is the freedom of what is observed to initiate a new action. Thus the uncertainty of the quantum of action is, or if you prefer, allows, purpose. It is analogous to the blank line on a check where you write in the amount.

Here we must answer the criticism of biologists and philosophers such as C. H. Waddington and Ernst Cassirer, who have insisted that the amount of energy in the quantum of energy is "too small to lift your little finger." This criticism is a failure to appreciate that all design engineering is based on the use of trigger energy. A machine would be useless if it took as much energy to control as the machine itself provides. That trigger energy can be made arbitrarily small, as in the case of the photoelectric cell that opens the supermarket door.

All living organisms are elaborate hierarchies: muscles controlled by nerves; nerves by chemical bonds; chemical bonds by photons, quanta of action. The principle of trigger energy thus removes the objection that the energy involved in the uncertainty principle is too small to account for free will. As we shall see, the small energy, with its long period, is a necessary condition for the life process to begin.

To review, then, intention is of major import in psychic phenomena. Further, intention can be correlated with the quantum of action. The uncertainty of the quantum of action confirms that correlation, because one's freedom of decision cannot be predicted by an observer.

The rest of the story falls into place almost of itself. Not only is the quantum of action in the form of photons responsible for all atomic and 
molecular interaction and for the very creation of material particles, it is responsible for the purposive thrust of evolution, the continuity without which the universe would be a mere subsiding agitation of billiard balls.

\section{A Model for Consciousness}

I have elsewhere (Young, 1976) shown that since the quantum of action is an oscillation or rotation at a certain frequency, we can view each cycle of that rotation as a cycle of action that goes through different phases. Note that this emphasis differs from the usual treatment of light as electromagnetic frequency or wavelength. The frequency, or cycles per second, is a property or quantity that can be measured and is extrinsic, whereas the position in the cycle is essentially qualitative, indeterminate, and intrinsic. Were we to think only in terms of frequency, we would have no more reason for associating electromagnetism with consciousness than we would have for associating billiard balls with consciousness, and we could retain the view that all matter is mechanical or electrical and has no relation to consciousness.

But what is consciousness? Obviously it is not a thing. Bertrand Russell said that the class of elephants was not an elephant. In somewhat the same sense, the consciousness of a thing it not a thing, that is, an object in space-time. In fact, one could say that consciousness is what you have when you don't have something. For most actions consciousness is not necessary. It is when intention is not followed automatically by its fulfillment that consciousness ensues.

The nature of consciousness becomes clear if we consider cyclings or frequency, as distinct from position in the cycle. In the case of sound, the note middle $\mathrm{C}$ is about 500 cycles per second (cps). If we lower the frequency about five octaves, we can still hear a frequency of $16 \mathrm{cps}$, about the lowest we can hear as a tone. A still lower frequency becomes a rattle. Imagine the frequency so low that we could watch the violin string moving from one extreme to another. Now imagine that our life spans were shorter than the period of the string. We might see the string beginning as a straight line, get more and more bent, and not know how far it will go, much as we watch the stock market go up and wonder when to sell. At some point it would stop going up and begin to fall. Only after a half-cycle could we begin to form some consciousness of the cyclic behavior of stocks, during which time we might have lost our savings, committed suicide, or even doubled our investment.

This uncertainty is involved in any cycle that is longer than a 
person's comprehension, and constitutes the part of life that takes our attention. It is these longer cycles that are of concern, that occupy our consciousness. Shorter, repeating cycles become objects of consciousness, and we don't worry about them. As with sound, the repeating cycle is heard as a single note. Thus each day has its dawn, its noon, and its nightfall; we don't worry about the day ending because there will be a new day tomorrow. Repetition makes it possible to define limits and hence turn unknowns into knowns, freeing consciousness for new problems.

It is the same throughout nature. The high frequencies characteristic of atoms absorbing and radiating photons in a gas are subsumed by lower frequencies corresponding to the binding energy of molecules, and these in turn by still lower frequencies characteristic of cells and multicellular organisms. There is thus a hierarchy of frequencies, with the lower frequencies, or longer periods, controlling the higher.

Planck established that energy times time is an invariant, Planck's constant, $h$. Thus a longer time is associated with lower energy. Evolution proceeds by a degradation of energy from nuclear particles, with an energy of one billion electron volts, through atoms and on to organic molecules with about $1 / 25$ of an electron volt, the energy of a particle in the temperature range that can support life. The organic molecules responsible for life processes such as metabolism thus are associated with units of action that have very low energy. These quanta constitute a bath of free energy upon which the vital energy can draw.

But why should life begin only after this enormous reduction of energy has occurred? The answer is that the lower energy is the price paid to get more time. That which has the longer time cycle can control cycles shorter than its own. At the molecular level, this makes it possible for the vital energy to avail itself of a wide range of materials for the initiation and direction of the life process.

This becomes apparent if we think of a cycle of action as a learning cycle. The learning cycle has four phases. It begins with (1) a spontaneous or unconscious action, such as a child reaching out and touching a hot stove. The pain causes (2) immediate withdrawal or unconscious reaction, followed by (3) an awareness that the stove caused pain, a conscious reaction, followed by (4) future avoidance of hot stoves, a conscious action, or control. Thus the child learns. If the experience is not learned, the cycle repeats until it is, after which the child moves to a higher level involving more complex or longer-term cycles, always incorporating what he or she has learned and building a hierarchy of automatic reactions controlled by the brain.

Consciousness is always at the leading edge of that growth process, 
always pressing on. This lays the basis for higher consciousness. There is a consciousness appropriate for each level of interaction, from that of nuclear particles to that of the higher organisms, and there is no reason to suppose that it stops there.

It is important to point out that the learning cycle includes consciousness and action. No matter how expert we become, we still have something to learn, and that learning or consciousness comes only after an exploratory action has exposed some error. We can then rectify the action and get on with it. The physicist may not be good at philosophy, but he or she can at least make mistakes and possibly learn from them. The philosopher has no way to recognize whether a mistake has been made. The vocabulary of science has shown us that intention has a proper place in the formalism of physics, and by emphasizing the cycle of action it becomes possible to obtain a model for the growth of consciousness, and with it the evolution of life.

\section{Soul}

Our correlation of intention and consciousness with light, it is important to add, was not a correlation with electromagnetism, which is a theory of light. Nor was it even a correlation with the photon as currently thought of as a particle, but with the cycle of action, which is implicit in both theories but emphasized in neither.

If we are to say that consciousness is $x$, there must be something known about consciousness and something known about $x$ that, when equated, cause more to be known about both. Thus to say that consciousness is a different dimension is meaningless. To say that it is light may be intuitively gratifying, but still only a metaphor. But to find from science that the "vibration" of light is a rotation, a cycle of action that goes through mutually opposing phases, and at the same time to recognize consciousness as a byproduct of the learning cycle, which also goes through opposing phases, makes the equation of the cycle of action with the learning cycle not only meaningful but regenerative, in that it causes the interpenetration of one discipline by another.

But that equation is not enough. Perhaps the most difficult part still remains. How does this view of consciousness apply to the question of the continuity of the soul? The correlation just made enables us to see the following:

First, behind the things, molecules, cells, organs, etc., there is some agent that changes the state of molecules, cells, organs, etc. Secondly, 
that agent is light, the photon or quantum of energy, which conveys a very small amount of energy that can trigger specific reactions and control their timing. Thirdly, longer-period quanta can control shorterperiod quanta, because being longer they can "comprehend" or subsume what is shorter than their own period, and hence control the shorter-period and greater-energy activities of their environment.

Fourthly, degradation of energy, or descent into matter, that produces atoms and then molecules, creates a great variety of molecular material with new combinations forming and dissolving. These combinations are sensitive to temperature. Finally, at this point the stage is set for life. The quanta with the longer period can begin to sort energy, create order, and build organisms. Something comparable to awareness has been present all along, but awareness of cause and effect, which requires a longer period than the cause to take effect, is only now possible.

Life so construed implies evolution, whose higher stages follow. This I discussed in The Reflexive Universe (1976), where I used the idea of the "great chain of being" to support the continuity of a single evolving entity, progressing through increasingly advanced stages of evolution.

The learning cycle, which makes consciousness possible, stores the learning of previous cycles in a memory bank that ceases to be conscious. Thus we learn to spell, then to write, then to type, each stage, when it is learned, becoming automatic and no longer conscious. But we still face the problem of how a distillation of memory can carry over from one lifetime to another through the successive stages of evolution, and for that the soul is a necessary vehicle.

For plants, the "soul memory" is not a factor. The learning cycle at that stage has to do with how cells are manufactured and reproduced. That is a function of deoxyribonucleic acid (DNA), the prototype blueprint that replicates with each generation, and thus ensures continuity of form within the vegetable kingdom. There is thus no "soul" of the plant to survive; it is the pattern of the multicellular plant that survives in the genetic legacy of the species.

In animals the learning cycle produces a program of behavior that survives, when it meets evolutionary requirements, as instinct, in the "group soul" of the species. Instinct thus depends on memory, a program of steps necessary to the successful solutions of problems. That is different from DNA, which is a plan for manufacture, much as the blueprint of an automobile differs from the experience and ability of the driver. The growth and persistence of the group soul makes instinct the evolving principle of the animal kingdom. There the individ- 
ual animals, like the multicellular plants, are temporal manifestations and do not endure.

Humans are different still. We use memory, but do not depend on it alone. We can operate by reasoning from premises, which is to say we can recognize laws and use them to increase our scope-in other words, to think for ourselves. Such thinking is not dictated by instinct, but is acquired by personal effort, and the fruits of experience are stored in each individual soul. Recognition is essentially a spiritual activity, and it is spirit that moves and reforms the soul in humans.

That makes it necessary to distinguish spirit from soul. Spirit is the highest function. It manifests in intuition, purpose, the higher self, and other ultimates. Soul is its first vehicle, its access to experience, feelings, and values. Compulsive at first, it learns, with intellect, to serve spirit. It is that principle of the interpenetration of soul and spirit that keeps the light or consciousness from evaporating after death. It is in the nature of light to radiate, and without the soul to retain the values of experience, it would be indeed the smile without the cat.

With our limited understanding of ultimate reality, the correlation of consciousness with light via the cycle of action doesn't explain the after-death state. I once thought that since the photon was outside of time there was no problem with its endurance, but it could be said that because it is outside of time it does not endure.

In any case the soul and the mind are necessary intermediate principles between spirit, the active site of consciousness, and body. Note that what endures is not mind in the sense of accumulated knowledge, that is, intellect or ego consciousness. Forty years ago I asked the question: "How does the soul grow?" The answer, if there is an answer, is that its growth consists of increased competence and increased profundity and sensitivity. That answer meets the objection that any other modification would narrow its scope. Competence can narrow its focus on some specialization, but it does so without the sacrifice of other abilities. The question of the growth of the soul is of course very important, and I will return to it.

The problem of memory, which is essential to growth, may be even more difficult than the problem of consciousness. Some assume that the computer can store memory. What the computer in fact stores is information that one can retrieve. But the kind of memory that concerns us here draws on experience. It is memory of feeling, of evaluation. It has its basis in emotion and cannot be conveyed by information except insofar as the receiver is moved by the message. That soul 
language or mythos is the basis of poetry, drama, and other arts, and it draws on symbolism and metaphor, not information.

The standard criticism of the computer is that it cannot feel. The computer enthusiast doesn't put much stock in that objection; he or she would say it is unimportant because feeling is not necessary, or can be encoded. While that is not an answer, the only way to prove that it's not an answer is to unplug the computer. Without a power source the computer cannot function. The power source, unlike the soul, does not evolve, but it does motivate the computer, and hence has for the computer the same role that the soul has for the person or the animal: it makes it go. So we can add motivation as another function of the soul in addition to memory. Related, and necessary to both, is the dimension of time, one definition being "that which promises to fulfill one's expectations." That implies value, and hence attraction and repulsion. Illusion, a feeling that something is real, is part of this syndrome, but not in the limited and pejorative sense of delusion. Delusion is a mistaken interpretation of reality, but illusion is a necessary ingredient for motivation. If you were to see a movie as a succession of colored photographs of Hollywood actors, without the illusion that makes it a good story, you would not be getting your money's worth. Illusion is maya in the Hindu tradition, the "cause of rebirth." For other reasons I have used the word "binding" as descriptive of the soul function. We have the term "spellbinding," which comes from the Anglo-Saxon speilen, to tell a story.

In The Reflexive Universe (1976), I found that the most difficult part to discuss, let alone prove, was the reality of the soul. Rather than introduce the notion of the soul in the chapter on humans, where other difficult points were to come up, I went into the issue in the chapter on the animal soul. That was where it belonged, to be sure, because the principle that emerges with animals, responsible for the animal power of mobility, is not so much the animal body, a cellular organism like the plant, but the group soul of a particular species. I mentioned Eugene Marais's work on termite colonies, where he found that even if a glass plate were used to separate a section of the colony from the queen, an injury to that section would invoke responses from the entire colony. On the other hand, if the queen were removed, the coordinated activity of the whole colony broke down.

I also mentioned a series of experiments in which William McDougall trained successive generations of rats to go through a maze, and found that the later generations learned faster. But then it was found that rats in Australia, not descended from the trained rats, also learned faster. It was some years later that I read Rupert Sheldrake's 
work A New Science of Life (1981), in which he devoted a chapter to McDougall's work on rats. Sheldrake used the concept of a "morphogenetic field" to describe how the impress of this learning is transmitted to other rats, but I prefer the idea of a group soul as used by the theosophist Annie Besant. Instinct and learning are programs of behavior, involving sequences of action, and so are not properly represented by a field, which, like a map, describes positions in space rather than in time.

For mankind, the group soul is still a factor, but it becomes something to overcome. Bodies are "government issue." The group soul, which animates the body, is an inheritance from the animal kingdom. Our task or challenge is to learn to think for ourselves, and that requires individuation or ego, what Georg Hegel called "alienation." This means that each person "grows his own," an individual soul that not only survives the body, for the same reason the animal soul survives, but causes and prescribes the next life. What is not resolved in one lifetime continues to motivate the next.

But soul and ego are vehicles: the ego temporary, the soul enduring; ego, the container, soul, the content. That content is distilled into spirit, which is the true focus of human evolution.

The principal reason for my conviction of the reality of the soul and its persistence through time, its immortality, is that the theory of process requires that in any process there must be something that, like mass-energy in physics, is conserved. The word substance has been so tortured by the inquisition of the philosophers (Rene Descartes, Baruch Spinoza, Gottfried von Leibnitz, and others) that it says whatever they want it to say. Nevertheless I find it difficult to find another word. But permit me to make a brief reference to my theory of process. That model describes any process as taking place on four levels through which it descends, then turns and ascends to its goal. There are thus seven stages, beginning with purpose and ending with goal. The intermediate stages of this process provide the means necessary to the achievement of this goal. While a five- or even three-stage model might suffice for simplified processes such as elementary communication, the argument for seven stages is put forward in The Reflexive Universe (1976).

As indicated in Figure 1, the worldly physical objects we can see, touch, hear, and smell, found at Level IV, result from giving form (Level III) to substance (Level II) according to a purpose (Level I). There are a great many exemplifications of this scheme, one of the most fundamental being the kingdoms of nature, as shown in Figure 2.

Important in the present context is that there is a certain symmetry 


\section{Figure 1}

\begin{tabular}{c|c}
\hline $\begin{array}{c}\text { Level I } \\
\text { Sp1rit } \\
\text { Purpose }\end{array}$ & $\begin{array}{c}\text { Stage 1 } \\
\text { Potential }\end{array}$ \\
\hline $\begin{array}{c}\text { Leve1 II } \\
\text { Sou1 } \\
\text { Substance }\end{array}$ & $\begin{array}{r}\text { Stage 2 } \\
\text { Binding } \\
\text { Value }\end{array}$ \\
\hline $\begin{array}{c}\text { Leve1 III } \\
\text { Mind } \\
\text { Form }\end{array}$ & $\begin{array}{c}\text { Stage } \\
\text { Ident 1ty. } \\
\text { Concept } \\
\text { Dominion }\end{array}$ \\
\hline $\begin{array}{c}\text { Level IV } \\
\text { Body } \\
\text { Object }\end{array}$ & \\
\hline
\end{tabular}

\section{Figure 2}

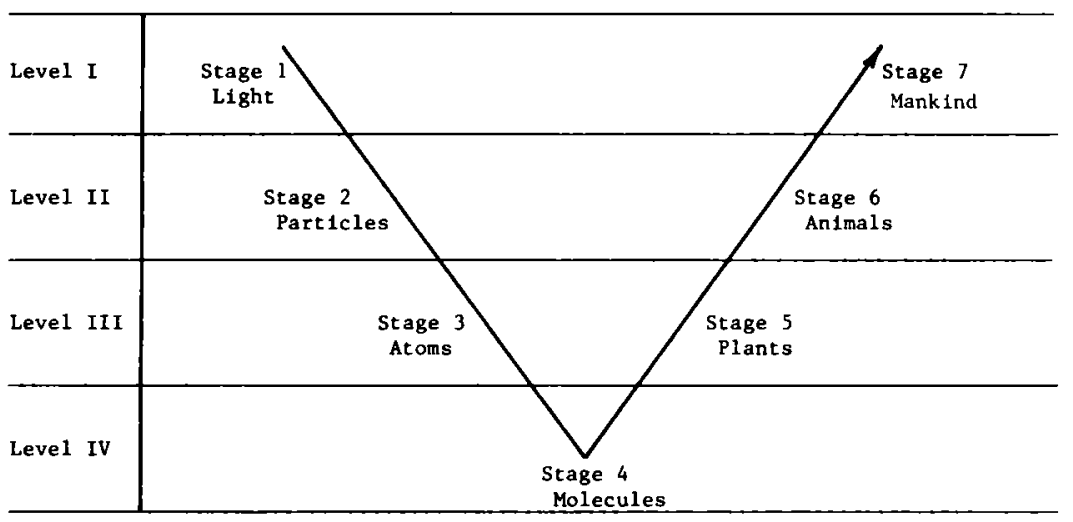

to the arc. The first and seventh stages are on Level I, but the first is goal as potential, and the seventh, goal achieved. The second and sixth stages share substance or value, the second enslaved by attraction, and the sixth able to employ it. For example, the electron, at the second stage, is forced to move by charge, whereas the animal, at the sixth, makes use of attraction, such as in mating rituals. The third stage is 
constrained by form, deprived of freedom in exchange for identity; the fifth uses form to organize and to reproduce identity, i.e., progeny.

The soul is Level II. It is liquid in the sense of liquid assets, like money or energy, not coins or bills but value, something real but not a material object. It is also motivation, that which stimulates and drives us over and above necessity. That drive is compulsive at the second stage, and its compulsiveness is overcome at the sixth.

Let us pause for a moment to get our bearings. What am I talking about? The four levels are categories or logical types. When Russell said that the class of elephants was not an elephant, he inaugurated the notion of logical types. Gregory Bateson said that the price of wheat was not an object, and made an important contribution by pointing out instances of confusion caused by failure to distinguish logical types; but he rejected my suggestions of additional logical types. Willard Quine's response to me was that there were arbitrarily many logical types. Russell, by 1938, had lost interest in logical types, and so far as I know, that idea has not been pursued or further developed since he distinguished between a class and its members.

The four levels are an extension of the notion of logical types. Level IV covers objects in the actual world: elephants, chairs, etc. Level III consists of concepts: the class or concept of "elephants" or "chairs."

Level II is the value and need for something, for elephants or chairs. It is what motivates us with regard to a thing, but it also covers what motivates the thing itself, as well as the material, the substance of which the thing is made. If that correlation is difficult (and Level II, being nonconceptual, is difficult to grasp), note that ordinary language uses the word "matter" to indicate substance as well as value: "such and such does not matter."

Level I is the purpose of an object, or the purpose we use it for. We could use a chair to stand on; the lion trainer uses it to keep the lion from attacking him. Because purpose is a free option, it cannot be defined or conceptualized. But therein lies its power: the value (Level II) of something is established by the purpose (Level I) for which it is used.

Quine said that there were arbitrarily many logical types. He may have based that on the fact that elephants belong to a larger class of mammals, and mammals to a still larger class of vertebrates. But these larger classes are not different logical types; they are still classification.

The contribution of the four levels to the question of the soul is that they enable us to get past the limits of conceptualization. We can admit the existence, or rather the importance, of aspects of reality that are 
not known through sense data or capable of definition. In fact, Levels I and II are both preconceptual, and both are nonobjective, that is, neither objects of sense experience (as in Level IV) nor concepts (as in Level III).

I have already given the value of money as an example of Level II. We can draw from science a number of its most fundamental notions, such as force, charge, and energy, and show how those too share this projective, nonconceptual nature.

\section{Survival}

One of the most fundamental principles of materialist science is the principle of conservation of mass-energy. The conservation of mass and the conservation of energy were initially two principles. They became one when it was recognized that mass and energy are interchangeable.

Now I usually use the conservation of mass-energy to support the immortality of the soul. Thus Level II is substance, which is formed by Level III to make objects, Level IV. Such objects, including our physical bodies and all things constructed by man, buildings, machines, etc., as well as plants and animals, can be destroyed, can die. Human cells have not only a built-in lifetime, but a predetermined limit to the number of times they can reproduce; thus a new organism will not continue to reproduce longer than its parent.

So if everything that can be constructed can be destroyed or destructured, how can the soul be immortal? The answer is that it is not constructed. Structure arises at Level III. The soul is simple substance, energy if you like, and if energy is conserved, so is the soul.

If we liken energy to the substance of the soul, we could liken mass to its troubles, its traumas, condensations of the otherwise free energy of the psyche. This would imply that memory is analogous to mass. Pursuing that tack we would see memory as the investment of free energy in what we would call the furniture of the self. Its sex, its identity, its position in the social structure (profession, avocation, and political, religious, and other affiliations) can be seen as concrete impediments, acquisitions necessary for living in the world but, in the last analysis, frozen or trapped energy that can become so burdensome that the soul gets stuck in matter, or in patterns of behavior or role playing, and can progress further only by dissolving its embodiments and regaining its freedom.

But the question still remains: How can the soul grow under the principle of conservation of mass-energy? We must remember that the soul is a means, and the question is not so much that of its own growth 
as it is of its alignment with, and suffusion by, spirit. It was the hunger of soul that initiated manifestation, eating the fruit of the tree, and when that hunger is appeased, the monad can move on toward its goal.

We cannot expect to resolve or even describe this advanced state from our present perspective. However, we can make use of evidence available from the stages of process. What I have not mentioned here, but did develop in The Reflexive Universe (1976), is that each of the seven stages of process has substages that partake of the same nature as the stages. An interesting finding in this context is that all seventh substages depend on the next stage. Thus, at the seventh substage of the atomic kingdom, the disintegration rate of radioactive atoms can be controlled by molar concentration; seventh substage molecules, DNA and virus, depend on cells for their replication; seventh substage flowering plants depend on insects.

Extrapolating from this, we can anticipate that human evolution, beyond the purely animal necessity of survival, is dependent on, and interrelated with, what is beyond mankind: superbeings or gods. And it is pertinent here that a belief in powers of a higher order, in gods or in a god, has characterized almost all peoples and cultures. The possible exception is modern Western culture, where the belief in science has tended to supplant the belief in gods.

As we are dealing with first principles, it is important to note that the difficulty involved is due not just to the intrusion of religion into science, but to the inversion of cause and effect. Our whole learning experience in the world is that a cause precedes the effect, and science is based on that self-evident axiom. So in these examples of a dependency on the next kingdom, something not yet there, we are going against what is reasonable or natural.

This comes to the fore in the case of human evolution. The concept of survival of the fittest, while deficient in that it does not explain how jumps to higher orders of evolution can occur, makes sense insofar as survival puts a premium on some forms versus others. With individual human evolution, the goal of survival is not sufficient. There has to be some transfinite dedication, some dedication to goals beyond the limit of a lifetime.

It might be said that there is already some evidence of this in animals in their care of their young, but that could be accounted for by instinct. The evolution of individual persons, which as we have pointed out is necessarily self-initiated, cannot be accounted for by instinct nor by DNA. It is learning to think for oneself that is essential to human evolution.

In this matter we should be on the lookout for clues from whatever source, and despite the fact that theosophists are currently in poor 
repute, I would like to mention that it was one of their claims that pet animals, by devotion to their masters, often are making the first step toward their evolution as persons. Devotion is above and beyond the requirements of necessity, and it paves the way for a different kind of evolution from that of the animal principle.

Whether that is true or not, it leads in the right direction, in that the emphasis is on emotion and motivation, Level II principles, which are not dealt with by science because its policy confines it to the objective, physical world of measurement and relationship structure. We are in fact dealing with things larger than ourselves, while science can deal only with what it can control.

This takes us back to my finding, described in the first part of this article, that intention is of major importance in the practice of healing, dowsing, and other psychic phenomena. I do not know whether there are other unrecognized types of energy, but in any case such energies, as well as those recognized by science, are directed and controlled by intention.

Intention has its correlates in the measure formulas of physics in action, the product of energy times time. It is the essence of selfhood, the elan vital of Henri Bergson. It is not a different kind of energy; it is the principle that directs energy. In reference to its formulation as energy times time, one may think of the time component as timing, equivalent to direction. In other words, a cycle can be thought of as taking place in time or space; timing is the phase or direction in that cycle.

We can now go a step further and correlate intention to spirit. Soul is the first precipitation of this spirit or essence into temporal being, into the world of becoming. Like Eve, it is the mother of all living, the matter or substance that can take on forms and produce the world of physical molecules that makes life possible.

The means, substance (soul), and the formed embodiments of substance, are thus first made available and then used by spirit to achieve knowledge of itself, not only through gaining competence in organizing matter, but through the transformation of meaning into the more imperishable values of the soul: the true, the good, and the beautiful.

\section{References}

Sheldrake, R. (1981). A New Science of Life: The Hypothesis of Formative Causation. Los Angeles, CA: Tarcher.

Young, A. M. (1976). The Reflexive Universe: Evolution of Consciousness. New York, NY: Delacorte. 